\title{
The new ionospheric station of Tucumán: first results
}

\author{
Michael Pezzopane $\left({ }^{1}\right)$, Enrico Zuccheretti $\left({ }^{1}\right)$, Cesidio Bianchi $\left({ }^{1}\right)$, Carlo Scotto $\left({ }^{1}\right)$, Bruno Zolesi $\left({ }^{1}\right)$, \\ Miguel A. Cabrera $\left({ }^{2}\right)\left({ }^{3}\right)$ and Rodolfo G. Ezquer $\left({ }^{2}\right)\left({ }^{3}\right)\left({ }^{4}\right)$ \\ ${ }^{1}$ ) Istituto Nazionale di Geofisica e Vulcanologia, Roma, Italy \\ ${ }^{(2)}$ CIASUR, Facultad Regional Tucumán, Universidad Tecnológica Nacional, Tucumán, Argentina \\ ${ }^{3}$ ) Laboratorio de Ionósfera, Instituto de Física, Universidad Nacional de Tucumán, Argentina \\ $\left(^{4}\right)$ Consejo Nacional de Investigaciones Científicas y Técnicas (CONICET), Buenos Aires, Argentina
}

\begin{abstract}
An Advanced Ionospheric Sounder, built at the Istituto Nazionale di Geofisica e Vulcanologia, Rome, Italy, was installed at Tucumán, Argentina, particularly interesting for its location, near the southern peak of the ionospheric equatorial anomaly. The aim of this installation is to collect a large number of continuous data useful both to study the dynamics of the equatorial ionospheric plasma and to develop reliable regional ionospheric prediction models. Moreover this ionosonde will contribute to the ionospheric database and real time knowledge of Southern Hemisphere ionospheric conditions for space weather applications. The ionosonde is completely programmable and two PCs support the data acquisition, control, storage and on-line processing. In this work the first results, in terms of ionograms and autoscaled characteristics, are presented and briefly discussed.
\end{abstract}

Key words ionosonde - ionospheric data - autoscaling - equatorial anomaly

\section{Introduction}

Since the early years of the last century, ionospheric measurements have played a significant role in studies concerning ionospheric physics and related phenomena. By analyzing an ionogram important ionospheric characteristics can be extracted, that can strongly contribute to the knowledge of physical phenomena such as radio propagation in ionized media, physical and chemical processes in upper atmosphere, ionosphere and magnetosphere coupling, and solarterrestrial relations. Furthermore, observation of

Mailing address: Dr. Michael Pezzopane, Istituto Nazionale di Geofisica e Vulcanologia, Via di Vigna Murata 605, 00143 Roma, Italy; e-mail: pezzopane@ingv.it ionospheric plasma and forecasting of physical phenomena connected to the Sun-Magnetosphere-Ionosphere-Thermosphere system holds a remarkable scientific interest with respect to Space Weather, because of the influence of these phenomena on satellite and terrestrial communications.

For such a purpose ionospheric sounders should have some distinctive features, especially oriented towards routine service, like Internet connection and the possibility to perform an automatic scaling of the recorded ionograms in real time.

The Advanced Ionospheric Sounder (Arokiasamy et al., 2002; Zuccheretti et al., 2003), built at the Istituto Nazionale di Geofisica e Vulcanologia, Rome, Italy (here abbreviated AIS-INGV) satisfies these requirements.

Like other recent sounders, AIS-INGV ionosonde is practically built around a PC and has been designed to fulfill certain physical characteristics such as the power reduction (around 200 $\mathrm{W}$ against several kilowatts of traditional sys- 
tems) and consequently weight, size, power consumption and hardware complexity. It exploits the computer resources to manage the sounding, the real time signal processing, data storing and sharing; it has also the capability to be remotely programmable. The basic work of this ionosonde

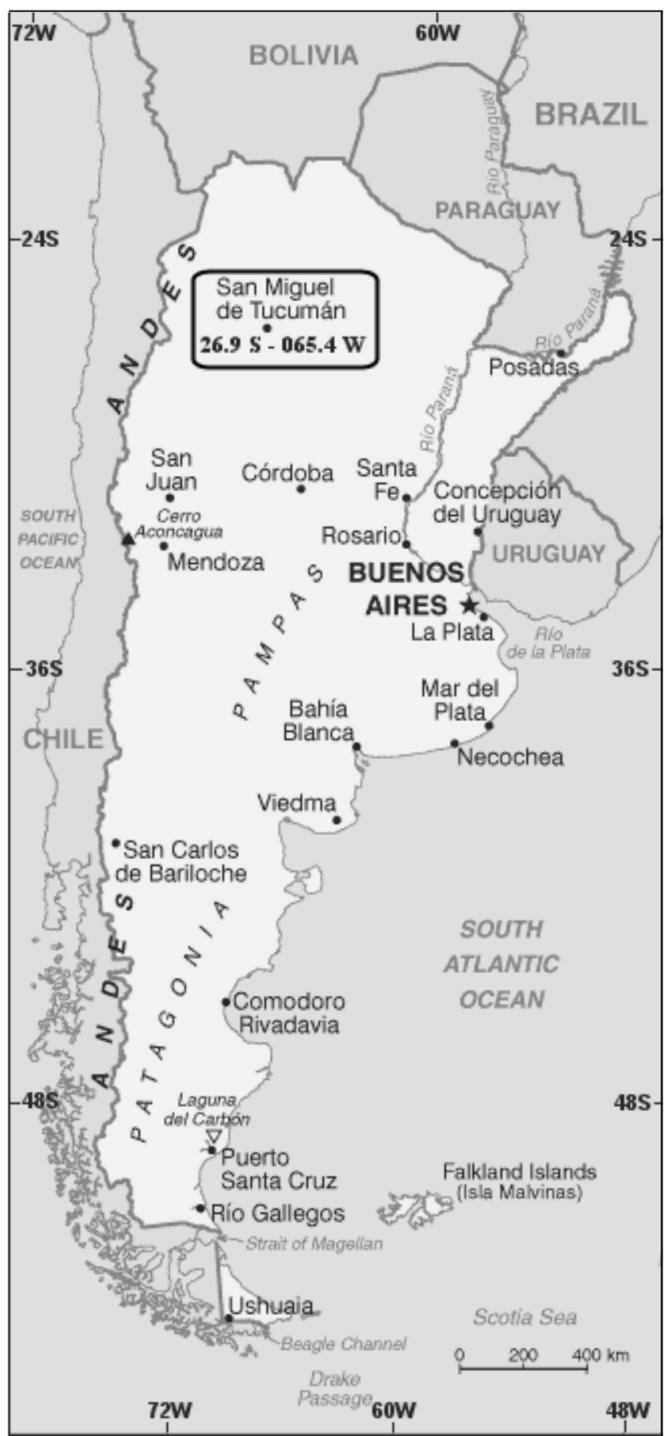

Fig. 1. Geographical location of the Tucumán ionospheric station. is to generate an ionogram from which virtual heights and critical frequencies can be scaled. But this ionosonde is also equipped with a software, called Autoscala (Scotto and Pezzopane, 2002), able to automatically scale in real time from an ionogram the following characteristics: foF $2, M U F(3000) F 2, M(3000) F 2, f x I$, foF 1 , $f t E s$, and $h$ 'Es.

Within the Italian-Argentine collaboration supported by the Istituto Italo Latino Americano (IILA), an AIS-INGV ionosonde was installed at Tucumán (geographical coordinates: 26.9S, 294.6E; magnetic coordinates: $15.5 \mathrm{~S}, 3.8 \mathrm{E}$ ), Argentina (fig. 1), near the ionospheric southern Equatorial Anomaly (EA) crest, at the end of August 2007. From 1957 to 1987 a first generation analog ionosonde operated at the same location contributing to the knowledge of the South American ionosphere. However the characteristics of the new ionospheric station are such that the data obtained can contribute significantly both to the study of the dynamics of the low latitudes ionosphere (for instance in terms of the occurrence of the equatorial spread- $F$, whose onset is strictly related to the EA development) and to built up reliable regional ionospheric prediction models for radio communications.

This paper briefly describes the main characteristics of the AIS-INGV/Autoscala system installed at Tucumán, and then it illustrates the first results of the operating ionospheric station, in terms of recorded ionograms and autoscaled characteristics.

\section{The AIS-INGV/Autoscala system: a brief description}

The aim of this ionosonde is to fulfil the demand to have a simple low-cost system to sound the ionosphere. To do this a system has been designed in which the most advanced HF radar techniques have been employed (Skolnik, 1981, 1990).

In order to compensate the power reduction, a 16 bit complementary phase code is employed (Golay, 1961) together with pulse-compression and a phase coherent integration, giving the possibility to investigate the ionosphere with a power of $200 \mathrm{~W}$ only. The ionosonde is com- 


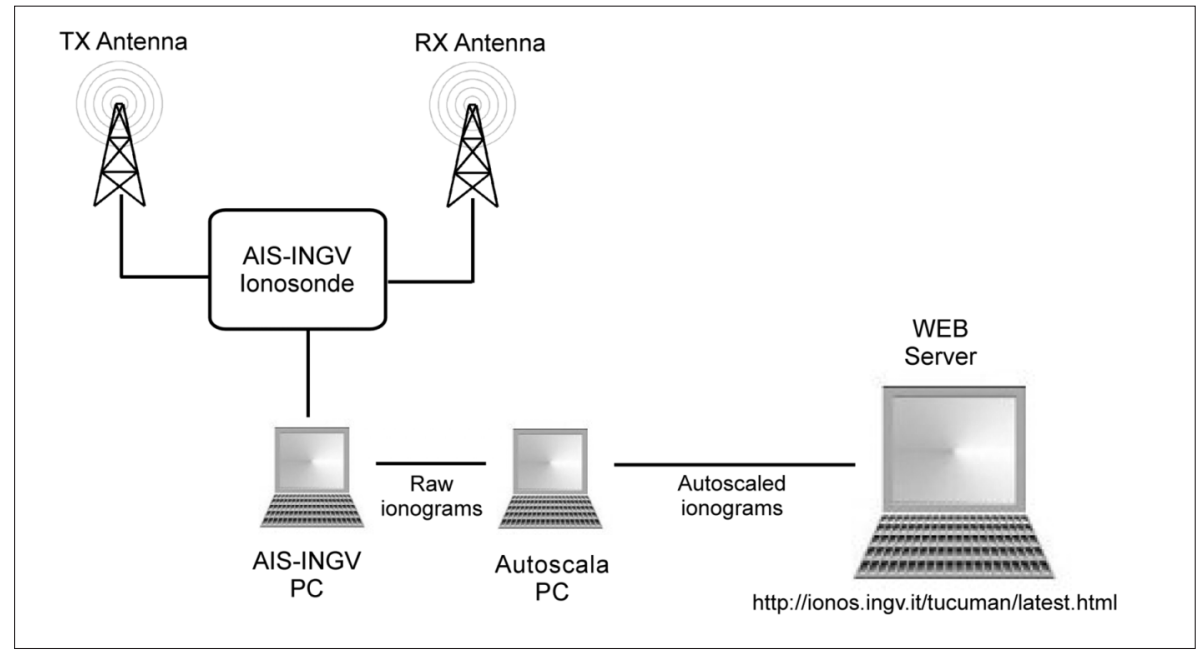

Fig. 2. The AIS-INGV/Autoscala system data flow.

pletely programmable and the data acquisition, control, storage and on-line processing are supported by a PC (Arokiasamy et al., 2002; Bianchi et al., 2003; Zuccheretti et al., 2003).

The antenna system is a typical crossed delta configuration in which a single backstayed mast sustains the radiative elements. They are $90^{\circ}$ oriented to limit the energy cross talk between transmitting and receiving antennas. The transmitting and receiving antennas have been built by engineers from the Facultad Regional Tucumán (FRT) of the Universidad Tecnológica Nacional (UTN); they are triangle shaped, $21 \mathrm{~m}$ high and $40 \mathrm{~m}$ long, fed by baluns and loaded by proper resistors. The loads are made up with special non inductive resistors to widen the band and to better direct the lobe upwards; the baluns create the proper match with $50 \Omega$ lines and power amplifier.

The product of the sounding process is a raw ionogram that is made available to be archived as well as to be processed real time by Autoscala operating in another PC (fig. 2). The characteristics given automatically as output by Autoscala are $f o F 2, M U F(3000) F 2, M(3000) F 2, f x I$, foF 1 , $f t E s$, and $h$ 'Es.

Autoscala is based on an image recognition technique, it does not use information on polar- ization, and it can then be applied to any kind of antenna system. Another important characteristic of Autoscala is its behaviour for ionograms characterized by a truncated trace; in these cases, if the digital information of the ionogram is considered sufficient, the software can reconstruct the absent trace, giving more reliable automatically scaled values.

Since the first phase of Autoscala development attention has been paid to the quantitative evaluation of the performance of the algorithms by comparing the output from Autoscala with the corresponding result obtained by a well experienced operator. These tests have demonstrated the reliability of the software both for quiet and for disturbed conditions (Pezzopane and Scotto, 2004, 2005).

Firstly Autoscala tries to identify on the ionogram the $F 2$ layer. In order to do this, the ionogram is initially memorized as a matrix. Then two empirical curves, that are able to fit the typical shape of the $F 2$ trace, and characterized by several parameters, are defined (Pezzopane and Scotto, 2007a). For each set of curves the local correlation $C$ with the recorded ionogram is calculated making allowance for both the number of matched points and their amplitude. The set of curves having the maxi- 
mum value of $C$ is then selected. If this value of $C$ is greater than a fixed threshold $C_{t}$ the selected curves are considered as representative of the $F 2$ trace. foF 2 and $M U F(3000) F 2$ are then obtained from the selected curve representing the ordinary ray, foF 2 as the frequency of the vertical asymptote, while $M U F(3000) F 2$ is numerically calculated by finding the corresponding tangent transmission curve. $f x I$ is obtained as the frequency of the vertical asymptote of the selected curve representing the $F 2$ extraordinary ray. $M(3000) F 2$ is simply the ratio between the calculated $M U F(3000) F 2$ and $f o F 2$. On the contrary if $C$ does not exceed $C_{t}$ the $F 2$ layer autoscaling routine considers the digital information of the ionogram not sufficient to establish whether the $F 2$ trace is visible on the ionogram, and the output for $f o F 2, M U F(3000) F 2, M(3000) F 2$, and $f x I$ will be N/A (Not Available).

The algorithm developed to identify the $F 1$ layer automatically (Pezzopane and Scotto, $2007 \mathrm{~b}$ ) is very similar to the one used for scaling the $F 2$ layer. The main difference is that unlike the $F 2$ layer autoscaling procedure, which is based on the identification of both ordinary and extraordinary rays, this procedure tries to fit only the $F 1$ ordinary ray by using a set of parabolas. For each parabola the local correlation $C$ with the recorded ionogram is calculated making allowance for both the number of matched points and their amplitude. The parabola having the maximum value of $C$ is then selected. If this value of $C$ is greater than a fixed threshold $C_{t}$, the selected parabola is considered representative of the $F 1$ ordinary ray. Once the parabola considered as representative of the $F 1$ ordinary trace is selected, $f o F 1$ corresponds with the frequency of the point of this parabola which has the highest virtual height. On the contrary, if $C$ does not exceed $C_{t}$ two alternative outputs for $f_{o F} \mathrm{I}$ are possible: NO if the $F 1$ cusp is not observed, or N/A if the digital information of the ionogram is considered not sufficient to establish whether the $F 1$ cusp is present or not. It is important to point out that the $F 1$ layer autoscaling routine is not able to function if the $F 2$ layer has not been identified. This because the algorithm needs as input parameter the minimum virtual height of the $F 2$ ordinary trace.

In addition, the routine to automatically scale the $E$ sporadic (Es) layer (Scotto and Pez- zopane, 2007) has been developed along similar lines to the $F 2$ and $F 1$ layer routines. If only the ordinary component is recorded the output corresponds to foEs, while if only the extraordinary component is recorded the output corresponds to $f x E s$. The ionograms recorded by AIS-INGV show both components and as a consequence the Es routine limits itself to give as output $f t E s$ (defined as the top frequency of the Es layer according to Wakai et al., 1987) being unable to specify this value as foEs or $f x E s$. The technique relies on a set of curves having the typical shape of the Es layer. Appropriate bounds for the height and the frequency are set. In particular curves having maximum frequency lower than the modelled critical frequency $f o E$ of the normal $E$ region are not considered. For each curve the local correlation $C$ with the recorded ionogram is calculated with allowance made for both the number of matched points and their amplitude. The curve having the maximum value of $C$ is then selected. If this value of $C$ is greater than a fixed threshold $C_{t}$ the selected curve is considered representative of the $E s$ trace. The value $f t E s$ is thus obtained as the maximum frequency of the curve together with the associated height $h^{\prime} E s$. On the contrary if $C_{t}$ is not exceeded then the routine assumes the Es trace is not present on the ionogram and the output for ftEs and $h$ 'Es will be NO.

The processing time of Autoscala is approximately $50 \mathrm{~s}$ on a computer with $1.60 \mathrm{GHz}$ processor and $512 \mathrm{MB}$ of RAM.

\section{The ionospheric station of Tucumán: its importance and first results}

The EA is characterized by two enhanced plasma crests on both sides of the magnetic equator at about $\pm 20^{\circ}$ magnetic latitude. The electrodynamic drift theory has successfully explained the main features of the EA. According to this theory, north-south geomagnetic field combined with the day-time east-west ionospheric electric field (both fields parallel to the surface of the Earth at the equator) creates a plasma fountain rising up to several hundred kilometers. This upward drifting plasma, when losing its momentum, it moves under gravity along the geomagnet- 
ic lines to higher latitudes creating the crests. This fountain effect and the consequent anomaly may encompass more than $30^{\circ}$ latitude on either side of the magnetic equator. The plasma fountain and the anomaly exhibit north-south asymmetries with respect to the geomagnetic equator mainly due to field-aligned plasma flows caused by neu- tral winds (Titheridge, 1995). Balan and Bailey (1995) have studied the equatorial anomaly over Jicamarca (geographical coordinates: 12S, 76.8W; magnetic coordinates: $2.4 \mathrm{~S}, 4.9 \mathrm{~W}$ ) using the Sheffield University plasmasphere-ionosphere model and they have shown the possible existence of an additional layer, first called the $G$ lay-

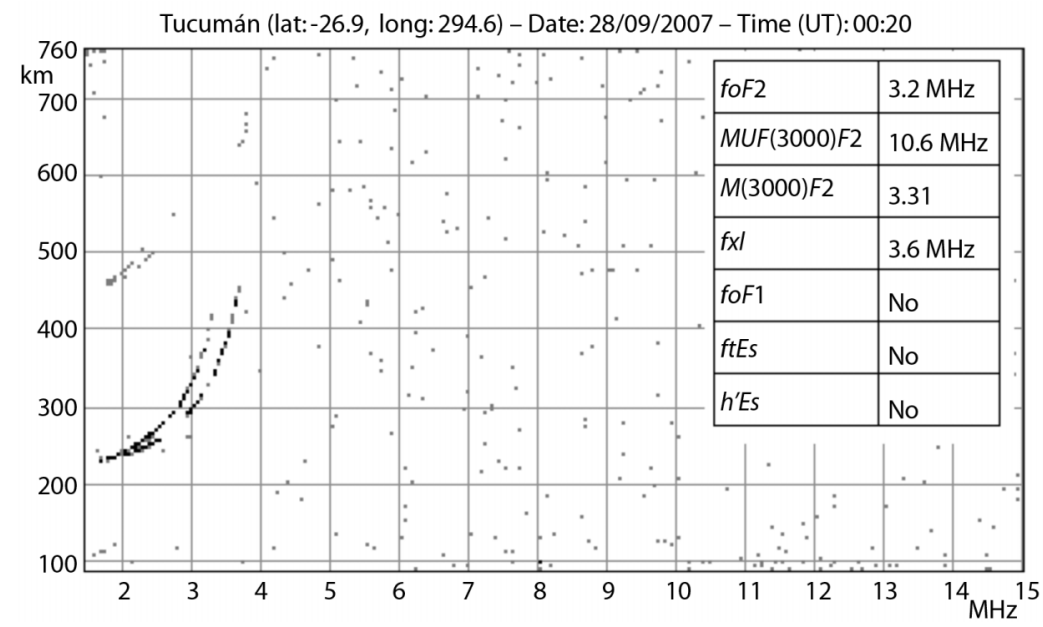

Fig. 3. An example of a nighttime ionogram recorded on 28 September 2007 at 00:20 UT by the AIS-INGV ionosonde installed at Tucumán, and autoscaled by Autoscala.

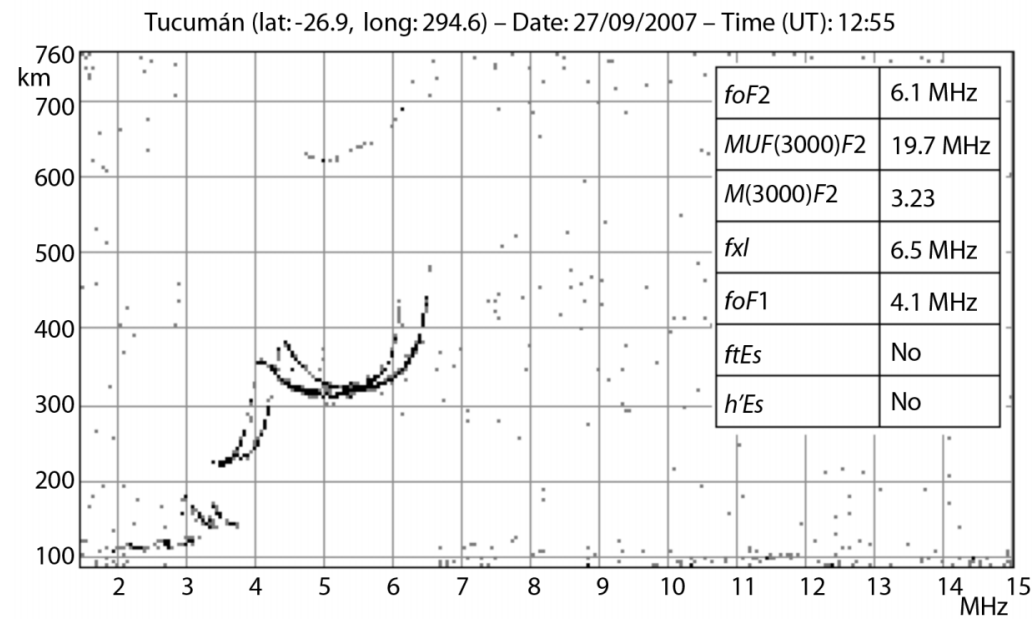

Fig. 4. An example of a daytime ionogram recorded on 27 September 2007 at 12:55 UT by the AIS-INGV ionosonde installed at Tucumán, and autoscaled by Autoscala. 

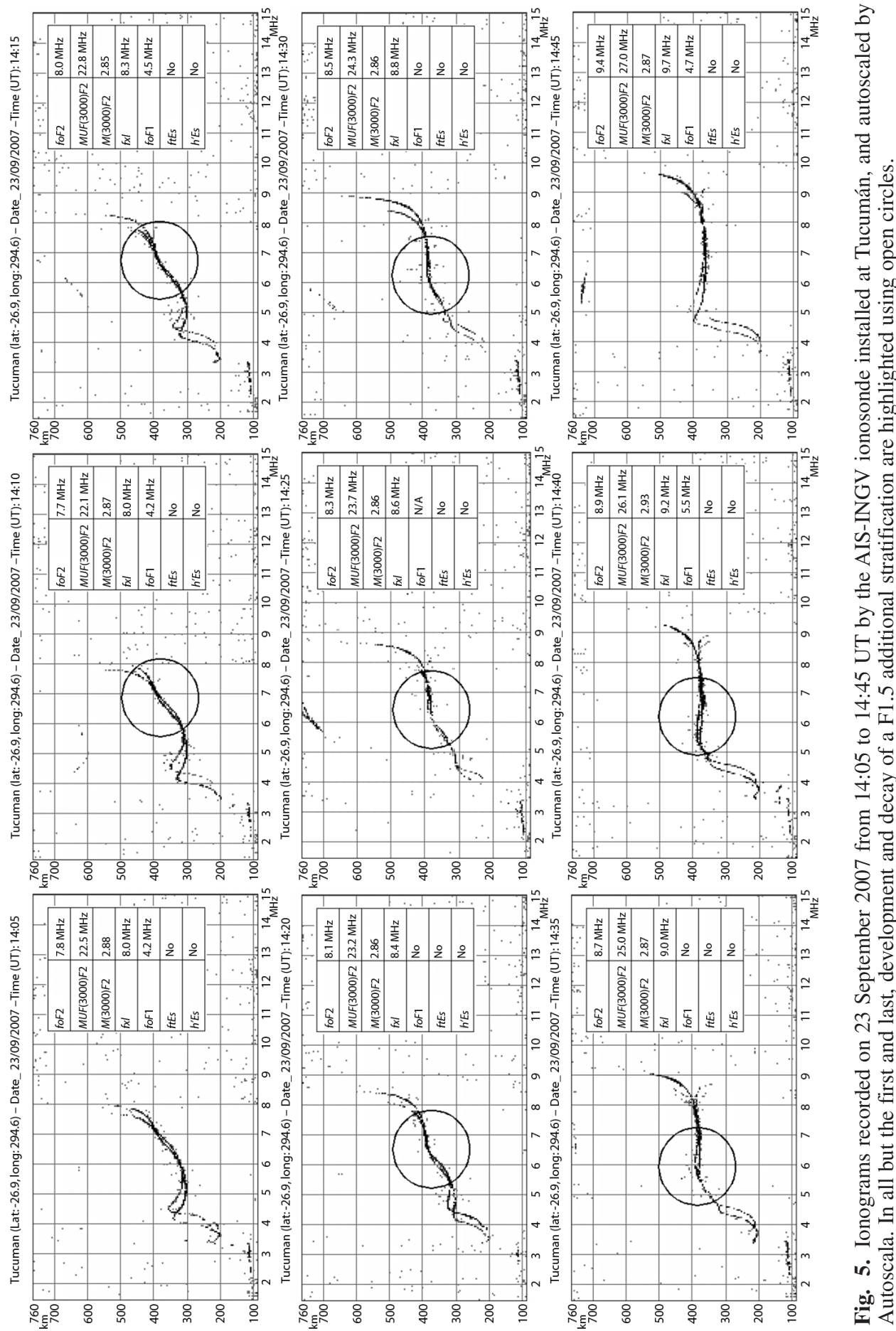
er, and now renamed the $F 3$ layer. Features and occurrence of this additional stratification have been observed and studied by Rama Rao et al. (2005), and Batista et al. (2002). Thampi et al. (2007) have also observed signatures of this additional layer in the latitudinal profiles of Total Electron Content (TEC). Additional stratifications occur also below the $f o F 2$ at low latitudes as reported by Lynn et al. (2000). These stratifications that do not alter the $F 2$ maximum conti- nuity are called $F 1.5$. In the light of all these recent studies, the location of the ionospheric station of Tucumán assumes a great importance because of the very limited number of operating ionospheric stations in South America, and also because this new ionospheric station is potentially able to generate and store a large number of continuous data.

Figures 3, 4, and 5 show examples of ionograms respectively nighttime, daytime, and with
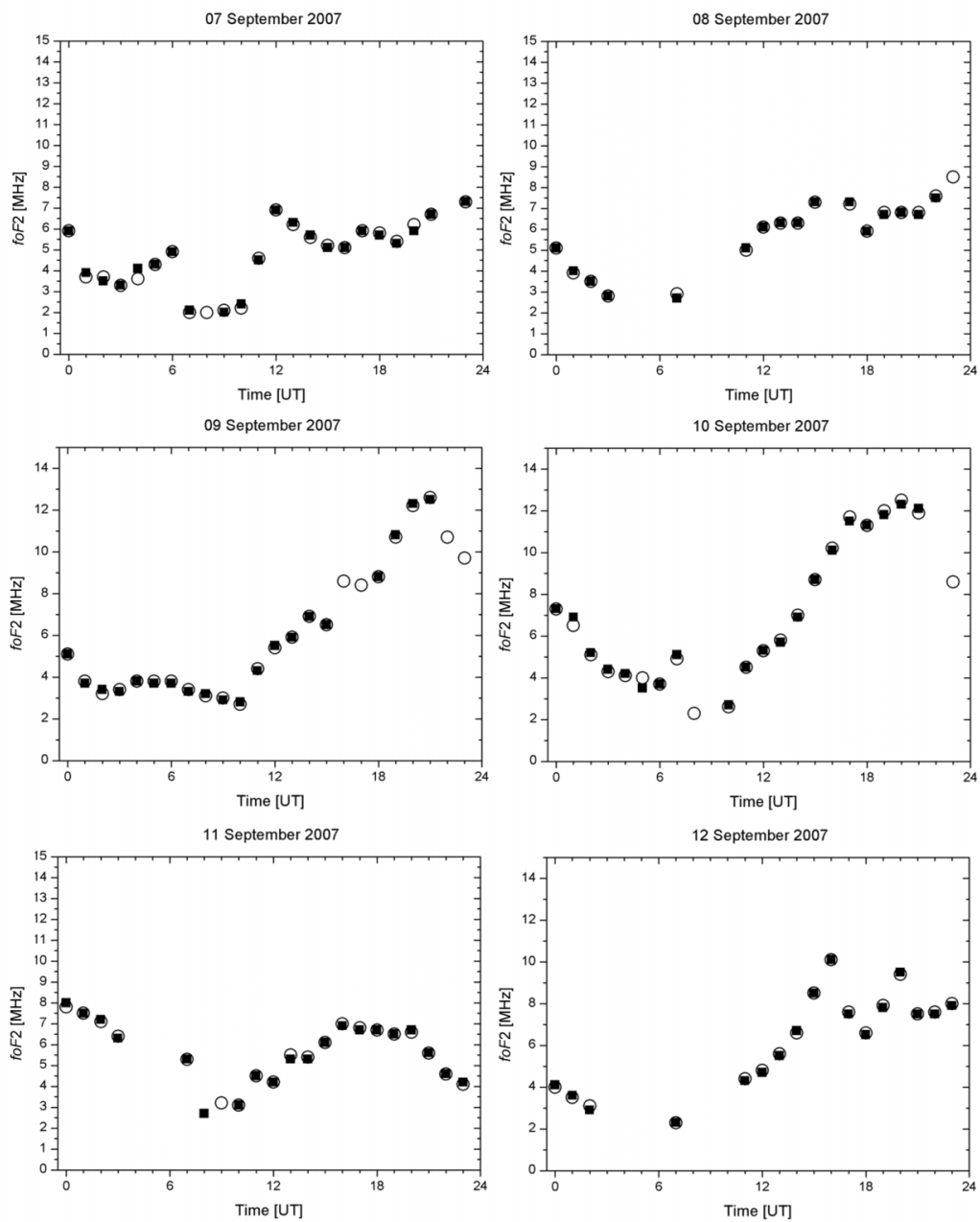

Fig. 6. Hourly foF 2 plots from 07 to 12 September 2007 as obtained by the ionograms recorded by the AISINGV ionosonde installed at Tucumán. Values manually scaled, and values obtained automatically by Autoscala, are indicated by open circles, and solid squares, respectively. 
possible additional stratifications, recorded by the AIS-INGV/Autoscala system installed at the new ionospheric station of Tucumán.

Although the ordinary and the extraordinary rays are very close, Autoscala succeeds in giving as output reliable automatically scaled values. As evidence of the reliability of the autoscaled values figs. 6 and 7 illustrate two sequences of six days, from 07 to 12 September $2007(K p=4+)$, and from 29 September to 04
October $2007(K p=5)$, for which the foF 2 values obtained manually are compared with the corresponding ones scaled by Autoscala. Even though both sequences of days are geomagnetically quiet, unlike the second one the first sequence presents a high day-to-day variability, typical at low latitudes, that is well matched by Autoscala. This points out that a long series of autoscaled data obtained at Tucumán can provide a valuable database for studying the day-
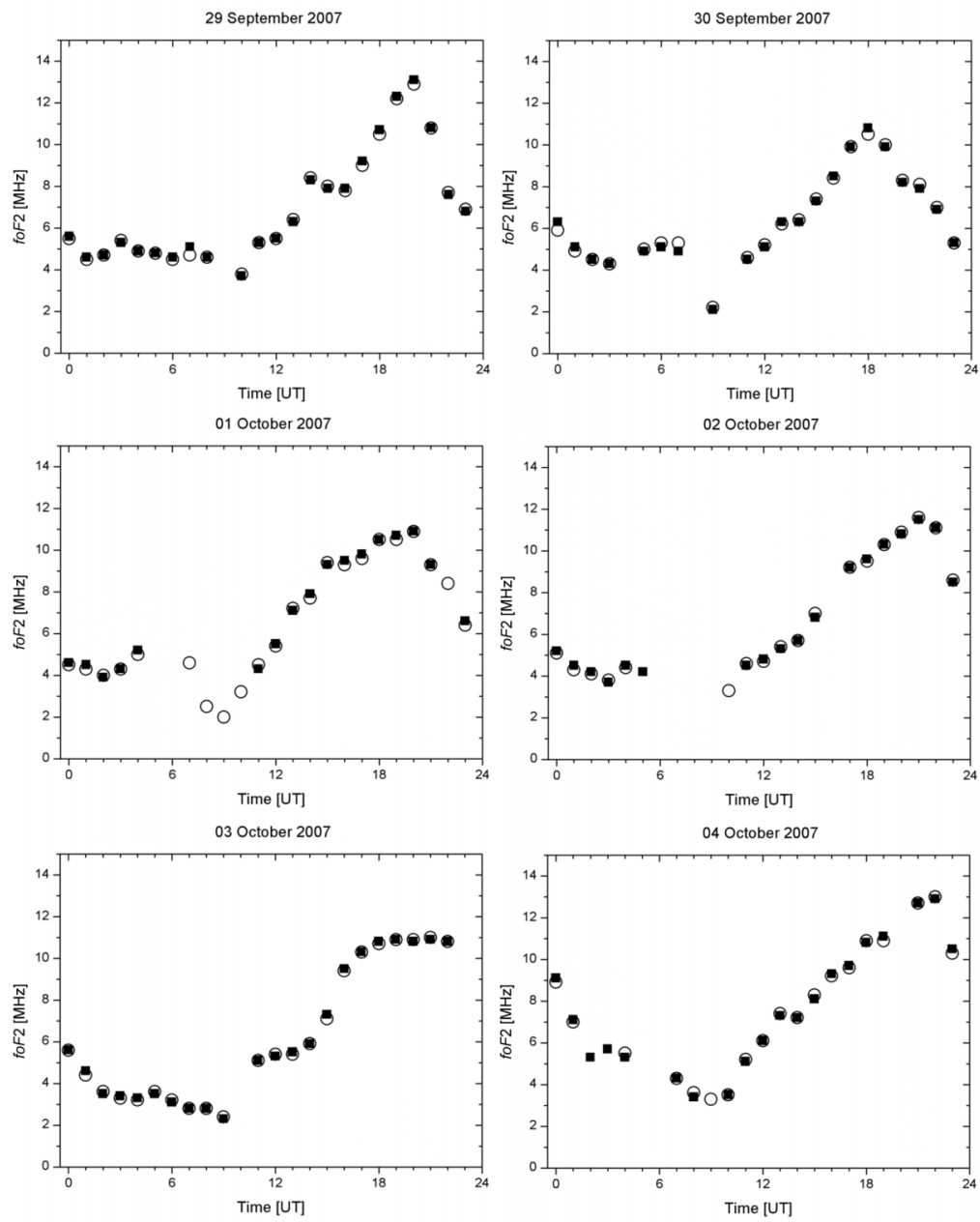

Fig. 7. Hourly foF 2 plots from 29 September 2007 to 04 October 2007 as obtained by the ionograms recorded by the AIS-INGV ionosonde installed at Tucumán. Values manually scaled, and values obtained automatically by Autoscala, are indicated by open circles, and solid squares, respectively. 

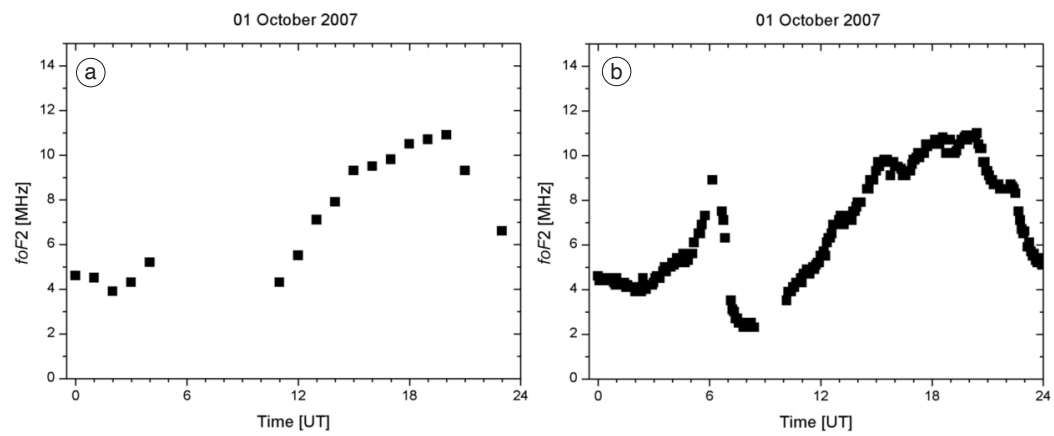

Fig. 8a,b. a) Hourly and b) $5 \mathrm{~min} f o F 2$ plots of 01 October 2007 as obtained by the ionograms recorded by the AIS-INGV/Autoscala system installed at Tucumán. In this case an hourly repetition rate hides an interesting phenomenon, from 05:00 to 08:00 UT, well visible on the contrary with a higher repetition rate.

to-day variability of the equatorial plasma, both for quiet and for disturbed conditions, which is to be still completely understood. The same database may also be used to develop reliable regional ionospheric prediction models.

Moreover, analysis of the autoscaled validated data has also led to interesting conclusions concerning the importance that the sounding repetition rate of the ionosonde has at these latitudes. In fact during the testing phase it has been seen that an hourly repetition rate could hide interesting phenomena well visible on the contrary with a higher repetition rate, as shown in fig. 8a,b.

\section{Summary}

This work describes the installation of a new ionospheric station at Tucumán, Argentina, particularly interesting for its location, exactly in the southern equatorial anomaly. The station was equipped with an AIS-INGV/Autoscala system, able to give as output autoscaled ionospheric values. For this reason the station can contribute to the ionospheric database and can be a part of a possible net for space weather purposes. On this subject it is worth noting that the real time $f_{o} F 2$ values produced by the station are already being used by the Australian IPS Radio and Space Services for mapping purposes (see the site <http://www.ips.gov.au/HF_Systems/ $6 / 5>)$.
To date, the ionograms recorded at the Tucumán ionospheric station by the ionosonde AISINGV, and autoscaled by Autoscala, are accessible real time through the site $<$ http://ionos.ingv.it/ tucuman/latest.html>.

\section{Acknowledgements}

The authors gratefully acknowledge Prof. Sandro Maria Radicella for his helpful suggestions.

\section{REFERENCES}

Arokiasamy, B J., C. Bianchi, U. Sciacca, G. Tutone and E. ZuccheretTi (2002): The new AIS-INGV digital ionosonde design report, INGV Int. Tech. Rep. No. 12 .

BALAN, N. and G.J. BAILEY (1995): Equatorial plasma fountain and its effects: Possibility of an additional layer, $J$. Geophys. Res., 100 (A11), 21,421-21,432.

Batista, I.S., M.A. Abdu, J. Macdougall and J.R. Souza (2002): Long term trends in the frequency of occurrence of the F3 layer over Fortaleza, Brazil, J. Atmos. Sol. Terr. Phys., 64 (12-14), 1409-1412.

Bianchi, C., U. Sciacca, A. ZirizzotTi, E. Zuccheretti and B.J. Arokiasamy (2003): Signal processing for phase-coded HF-VHF radars, Ann. Geophysics, 46 (4), 697-705.

Golay, M.J.E. (1961): Complementary series, IRE Trans. Inform. Theory, 7, 82-87.

LynN, K.J.W., T.J. HARRIS and M. SJARIFUdin (2000): Stratification of the $F 2$ layer observed in Southeast Asia, $J$. Geophys. Res., 105 (A12), 27,147-27,156.

Pezzopane, M. and C. Scotto (2004): Software for the automatic scaling of critical frequency foF 2 and 
$M U F(3000) F 2$ from ionograms applied at the ionospheric observatory of Gibilmanna, Ann. Geophysics, 47 (6), 1783-1790.

Pezzopane, M. and C. ScotTo (2005): The INGV software for the automatic scaling of $f o F 2$ and $M U F(3000) F 2$ from ionograms: a performance comparison with ARTIST 4.01 from Rome data, J. Atmos. Sol. Terr. Phys., 67 (12), 1063-1073.

Pezzopane, M. and C. Scotto (2007a): The automatic scaling of critical frequency $f_{o F}$ and $M U F(3000) F 2$ : a comparison between Autoscala and ARTIST 4.5 on Rome data, Radio Sci., 42, RS4003, doi: 10.1029/ 2006RS003581.

Pezzopane, M. and C. ScotTo (2007b): A method for automatic scaling of $F 1$ critical frequencies from ionograms, Radio Sci. (in press).

Rama RaO, P.V.S., K. Niranjan, D.S.V.V.D. Prasad, P.S. BRAHMANANDAM and S. GOPIKRISHNA (2005): Features of additional stratification in ionospheric $F 2$ layer observed for half a solar cycle over Indian low latitudes, J. Geophys. Res., 110 (A04307), doi: 10.1029/2004JA010646.

Scotto, C. and M. Pezzopane (2002): A software for automatic scaling of foF 2 and $M U F(3000) F 2$ from ionograms, in Proceedings of URSI 2002, 17-24 August 2002, Maastricht (paper 1018 of the electronic copy).
Scotto, C. and M. Pezzopane (2007): A method for automatic scaling of sporadic $E$ layers from ionograms, $R a$ dio Sci., 42 (RS2012), doi: 10.129/2006RS003461

SKolNIK, M.I. (1981): Introduction to Radar Systems (McGraw Hill, New York), pp. 581.

SkolniK, M.I. (1990): Radar Handbook (McGraw Hill, New York), pp. 1232.

Thampi, S.V., N. Balan, S. Ravindran, T.K. Pant, C.V. Devasia, P. SReElatha, R. SRIDHARAN and G.J. Bailey (2007): An additional layer in the low-latitude ionosphere in Indian longitudes: total electron content observations and modelling, J. Geophys. Res., 112 (A06301), doi: 10.1029/2006JA011974.

Titheridge, J.E. (1995): Winds in the ionosphere- $A$ review, J. Atmos. Sol. Terr. Phys., 57 (14), 1681-1714.

WaKaI, N., H. OHYAma and T. KoIZUMI (1987): Manual of Ionogram Scaling, 3rd version (Radio Research Laboratory Ministry of Posts and Telecommunications, Japan), pp. 119.

Zuccheretti, E., C. Bianchi, U. Sciacca, G. Tutone and B.J. Arokiasamy (2003): The new AIS-INGV digital ionosonde, Ann. Geophysics, 46 (4), 647-659.

(received September 24, 2007; accepted October 29, 2007) 